\title{
The February 24, 2010 substorm: a refined view involving a pseudobreakup/expansive phase/poleward boundary intensification sequence
}

\author{
Martin Connors ${ }^{1 *}$, Christopher T. Russell², Xiangning Chu ${ }^{2}$ and Robert L. McPherron ${ }^{2}$
}

\begin{abstract}
A substorm on February 24, 2010 was chosen for study by Connors et al. (Geophys. Res. Lett. 41:4449-4455, 2014) due to simple symmetric subauroral magnetic perturbations observed in North America. It was shown that a substorm current wedge (SCW) three-dimensional current model could represent these perturbations well, gave a reasonable representation of auroral zone perturbations, and matched field-aligned currents determined in space from the Active Magnetosphere and Planetary Electrodynamics Response Experiment (AMPERE) project. The conclusion was that substorm onset was at approximately 4:30 UT and that the substorm current wedge (SCW) formed in the region 1 (more poleward) current system.

Here, we examine the substorm in more detail, using ground optical data, more ground magnetic measurements, and in-situ measurements in the region of the substorm downward current by three Time History of Events and Macroscale Interactions During Substorms (THEMIS) spacecrafts. We apply magnetic inversion techniques and find that they agree with and complement optical data. We find that a sequence involving three previously categorized types of substorm-related response took place, that is, a pseudobreakup or weak expansive phase, followed by the full onset of a substorm expansive phase (EP), and in turn by a poleward boundary intensification (PBI) carrying the bulk of the SCW current. The initial activity was equatorward of that described by Connors et al. (Geophys. Res. Lett. 41:4449-4455, 2014) and began at 4:11 UT. The THEMIS spacecraft in the early morning sector detected magnetic field changes associated with the EP and PBI, aiding in differentiating them. The fuller picture suggests involvement of regions both relatively near the Earth and deeper in the magnetotail, in the overall substorm process.
\end{abstract}

Keywords: Substorms, Pseudobreakups, Expansive phase, Poleward boundary intensifications, Data inversion

\section{Introduction}

Magnetospheric substorms are an essential part of the cycle of energy storage and release due to the interaction of the magnetosphere with the solar wind, in which both dayside and nightside reconnections are currently understood to play an essential role (Angelopoulos et al. 2013). The episodic nature of the interaction was realized in the early work on analysis of magnetic fields (incidentally associated with aurora, which was mentioned

\footnotetext{
*Correspondence: martinc@athabascau.ca

${ }^{1}$ Athabasca University Observatories, 1 University Drive, Athabasca AB T9S 3A3, Canada

Full list of author information is available at the end of the article
}

only in a secondary way) of Birkeland (1908), who from his northerly latitude found "polar elementary storms". Their characteristics of predominance near local midnight, repeatability of "oscillation" of magnetic signature, "simultaneous perturbations, that are observable right to the equator", "short duration-not more than 2 or $3 \mathrm{~h}$ ", and "conditions before and after are comparatively quiet" can all be recognized as typical signatures of what are now called magnetic substorms. Birkeland was able to describe the three-dimensional nature of the main substorm current system with great accuracy, including deducing from magnetic considerations alone the approximate height of effective current flow in the ionosphere. Birkeland's stated aim was to do "a careful investigation of very simple

\section{Springer}

(c) 2015 Connors et al Open Access This article is distributed under the terms of the Creative Commons Attribution 4.0 International License (http://creativecommons.org/licenses/by/4.0/), which permits unrestricted use, distribution, and reproduction in any medium, provided you give appropriate credit to the original author(s) and the source, provide a link to the Creative Commons license, and indicate if changes were made. 
storms", and despite the extreme sparseness of magnetic observatory data available to him, this was attained to a remarkable degree.

The association of auroras with magnetic perturbations (as determined by a compass needle) had been established scientifically by Scandinavian researchers as early as the mid-eighteenth century (Potemra 1985) (and references therein). The development of the concept of "auroral substorm" and its association with "polar magnetic substorms" is described by Akasofu (2004) and can be regarded as a result of improved instrumentation during the 1957-1958 international geophysical year (IGY). Using arrays of all-sky cameras, Akasofu (1964) outlined the features of the expansive and recovery phases of the auroral substorm on a large scale and linked them to magnetic perturbations, noting in particular that intense aurora in the form of "surges" can be associated with negative changes in the northward magnetic component. McPherron (1970) added the growth phase to the description of substorms based primarily on ground and space magnetic signatures and related the ensemble of observations to changes in the magnetosphere as a whole. When the larger set of phenomena is considered, these changes lead to the concept of a "magnetospheric substorm" with the auroral and magnetic substorms as its historically first observed manifestations.

This paper focusses on the auroral and magnetic aspects of one substorm, originally chosen by Connors et al. (2014), with considerations similar to those of Birkeland, because of its apparent simplicity. Our enhanced analysis brings out some aspects of substorm phenomenology that go beyond the growth-expansion-recovery phases in ways that we now detail. Heppner (1954) had performed pre-IGY studies in the Alaska sector relating magnetic perturbations to reports from visual observers about auroral forms. The latter were displayed as a function of time and latitude in a way reminiscent of a keogram (see below). The growth phase signature of equatorward moving homogeneous arcs was described, but the key point in substorm development (the overall magnetic pattern being referred to as a "magnetic bay") was when the southernmost arc "breaks" into rayed forms or diffuse aurora. This gave rise to the term "breakup" as the start of the expansive phase or, in more recent times, the term "onset" (Rostoker et al. 1980; Rostoker 2002). Elvey (1957) found using all-sky cameras that it was not always the southernmost arc that broke up but could be one within the center of the auroral zone: this he defined as a "pseudo-breakup". Akasofu (1964) associated rapid poleward motion of the brightening arc with the start of the expansive phase but noted that in the case of weak substorms, and often if it was not the southernmost arc that activated, the poleward motion did not last long, terming this the "pseudo break-up". Whereas such pseudobreakups are near the equatorward border of the auroral oval or possibly in its center, there was later found to be systematic activity near the poleward border also. "Poleward boundary intensifications" or PBI (Lyons et al. 1999) show magnetic signatures and aurora there. We will take the phases of the substorm to be growth, expansion, and recovery and regard the types of auroral activity taking place during substorms to consist of growth phase arcs, pseudobreakups, breakups or expansive phase onsets, and PBIs. These are not exclusive classifications but appear to reflect terms used in the literature and having relatively clear definitions. We proceed to examine previous literature about the types of activity in substorms.

Lyons et al. (2002) used the spectrally discriminated meridian-scanning photometers and all-sky imagers of the Canadian CANOPUS project to find that a new arc formed and subsequently brightened from the equatorward border of the pre-existing auroras at onset. The time to brightening was typically a few minutes, with the brightening dramatic after that time. Of 11 cases of onset identified in this manner, 7 were pseudobreakups in which the new arc did not move significantly poleward and in which a full expansive phase did not occur. Liang et al. (2008) took advantage of high frame rate (3s cadence) allsky imagers to refine the view of the onset arc, which they found could either be newly formed or pre-exisiting, to show a large degree of structure, so that "auroral breakup" usually had a periodic form. Rae et al. (2009) used magnetic pulsations in the 24-96-s period band (refining previous practice of regarding Pi 2 band, 40-150-s period, as reflecting onset) to define onset time for an isolated substorm on March 7, 2007. Keograms from all-sky imager data showed formation of an arc at onset time at the station showing the earliest pulsation signal. Approximately 1 min later, a similar arc formation and pulsation onset was seen one MLT zone to the west, and about 5 min after arc initiation at either MLT, rapid poleward motion and brightening of auroras were observed. Rae et al. (2010) related spatio-temporal structure in breakup aurora similar to that found by Liang et al. (2008) to ULF magnetic activity in a way that was inferred to reflect inner magnetospheric plasma instability. Sergeev et al. (2005) used spacecraft imaging and ground magnetometer data to identify what was referred to as a pseudobreakup (PBU) at 21:06 UT on September 8, 2002, followed by a main onset at 21:18 UT. In this case, the pseudobreakup did not have a significant optical signature but did cause a magnetic enhancement after a growth phase characterized through one-dimensional upward continuation as having taken the auroral oval about $3^{\circ}$ equatorward in about $6 \mathrm{~min}$. In the $12 \mathrm{~min}$ between pseudobreakup and main onset, the magnetically indicated electrojet remained near the latitude of the PBU, and only after a period characterized by Pi 2 band pulsations did it move northward, at 
about 21:24 UT, with significant enhancement of current across the meridian only at 21:27 UT, when the electrojet attained the pre-growth-phase latitude. A study of an isolated pseudobreakup by Yao et al. (2014) showed that the physics of pseudobreakups appeared similar to that of substorms. Despite an auroral brightness increase several hundredfold out of the noise level, the electric current in the event peaked at approximately $70 \mathrm{kA}$ (magnetic perturbations of tens of nanotesla), well below that of substorms.

Although pseudobreakups could explain situations with magnetic or auroral activity prior to expansive phase onset, another possibility is that two or more onsets may occur, possibly with the latter one or ones dominating the overall substorm. Rostoker (1968) noted such precursory activity in auroral zone magnetic bays and auroral and subauroral Pi 2 records, calling the precursory activity a "trigger bay." Rostoker (2002) examined two onsets on March 28, 1996 as identified from auroral zone bays, auroral zone Pi 2, and meridian-scanning photometer records of multispectral auroral radiance, finding that the first constituted expansive phase onset and the second, larger event (ca. $450 \mathrm{nT}$ as opposed to $200 \mathrm{nT}$ ) was a poleward boundary intensification. Murphy et al. (2014) studied two substorms on April 9, 2011 during the interval 4-7 UT, using ground optical, magnetic, and riometer data, and space data from near-conjugate Time History of Events and Macroscale Interactions During Substorms (THEMIS) and Geostationary Operational Environmental Satellite (GOES) probes. The second substorm was found to consist of two activations, with onset timing derived from auroral intensity at different ground stations. The initial activation was equatorward of the first and preceded it by approximately $15 \mathrm{~min}$. It featured over $300 \mathrm{nT}$ of magnetic perturbation at more equatorward stations, significant azimuthal and latitudinal expansion, and strong injection signatures and dipolarization at synchronous orbit, thus would not be considered to be a pseudobreakup. Only slightly beyond geosynchronous orbit, three THEMIS probes did not detect injections or flows until the second activation. The authors concluded that either an inner or outer region of the geomagnetic tail could destabilize, possibly by a plasma instability in the inner region and involving the near-Earth neutral line (NENL) in the outer. On the other hand, $\mathrm{Pu}$ et al. (2010) examined the prototypical substorm of February 26, 2008 (Angelopoulos et al. 2010), finding that it had precursory activity which in many aspects resembled an expansive phase onset but due to weak magnetic signature (mainly determined through the AL index) and limited auroral expansion would have been a pseudobreakup despite occurring about an hour before the prototypical (ca. 04:50 UT) full onset. A further aspect of the relation of the outer to the inner magnetosphere arises from the observations of Nishimura et al. (2010) suggesting a relationship between auroral streamers, which are north-south arcs arising from PBIs, and substorm onset in more equatorward regions. Following up on a link to flows in the magnetotail, Lyons et al. (2012) examined the auroral effects of dipolarization fronts (abrupt, Earthward-moving structures inducing dipolarization in the $X=-20$ to $-10 R_{E}$ region of the plasma sheet), finding that these often took place after auroral onset, in some cases as much as 10 min after onset. To some degree, there seems to be ambiguity in the literature in distinguising pseudobreakups from initial onsets in a two-onset substorm, a point we must revisit below in classifying activity in the event under study.

The above considerations suggest that substorms are intrinsically complex, possibly to the point that Birkeland's (1908) hope to investigate "simple storms" must be confounded. Connors et al. (2014) claimed that the quantitative organization of data through the early space age model of the substorm current wedge (SCW) allowed essential simplifications in an event already selected for clear and simple ground signatures. However, studies such as that of Murphy et al. (2013) suggest that there is complex structure within the SCW, structure which, for example, Rae et al. (2010) would relate to wave activity fundamental to the physics of substorms. It is thus germane to examine the event of Connors et al. (2014) in more detail. Before doing so, we summarize the above discussion to bring out essential points.

It is clear that most isolated substorms with clear driving by the solar wind exhibit a growth phase, expansive phase, and recovery phases and that the most essential aspect of solar wind driving is the enhancement of dayside reconnection, the single largest factor in which is a negative interplanetary magnetic field (IMF) $B_{Z}$ component (southward IMF). While the growth phase corresponds to storage of energy in the magnetosphere, and particularly in the magnetotail, the exansive phase corresponds to its release, with demonstrated examples (e.g. Angelopoulos et al. (2010)) of this being related to signatures of reconnection in the magnetotail. The recovery phase, which we do not examine in detail, corresponds to a return of the magnetosphere to a nominally lower energy state.

Within substorm ground phenomenology, auroral and magnetic activity have been most studied. In addition to the substorm expansive phase, which is characterized by intensification of auroras, their poleward motion, structuring or breakup of a pre-existing or newly formed arc, pulsations in or near the Pi 2 (40-150-s period) band, and magnetic signals dominated by strengthening of westward electric currents, there exist at least two other forms of well-organized behavior: the pseudobreakup (PBU) and the poleward boundary intensification (PBI). The relationship of either or both of these to the expansive phase 
remains a question of intense study. We now proceed to a description and analysis of the event of February 24, 2010, 3-6 UT, with the above framework in mind.

\section{Event overview}

At the end of a period of southward IMF, activity associated with a substorm occurred in the time period approximately 4:00 to 5:30 UT on February 24, 2010 (gray region in Fig. 1). Standard AL, THEMIS AL, ground perturbations in the North American sector, and Active Magnetosphere and Planetary Electrodynamics Response Experiment (AMPERE) space-derived current densities (Anderson et al. 2014) suggested to Connors et al. (2014) that the onset time was 4:30 UT (hereinafter referred to as the "nominal onset time"), with large-scale aspects of the event well explained using a quantified version of the SCW model of McPherron et al. (1973). Despite being able to extract useful parameters such as electric current in the substorm current wedge (SCW) for the event,
Connors et al. (2014) noted some discrepancies, notably that significant currents were indicated by ground magnetometers prior to onset, the evening sector upward field-aligned current (FAC) as detected by AMPERE outlived the SCW, and that conjugacy between the northern and southern hemispheres was less than expected. Here, we resolve the first issue, finding that detailed study of magnetic fields and optical signatures implies an earlier start to activity resembling an expansive phase than that found by Connors et al. (2014). We also find that the expansive phase itself had substructure, involving a PBI, which also had a marked signature in space. We present a detailed outline, including new substorm timing, and will return to the other issues in work to follow.

Figure 1 presents an overview of the solar wind driving during the event, with the nominal time of the substorm, 4:00 to 5:30 UT on February 24, 2010, shaded. This figure is similar to Fig. 1 of Connors et al. (2014) but presents a longer time interval and more data. Propagated OMNI
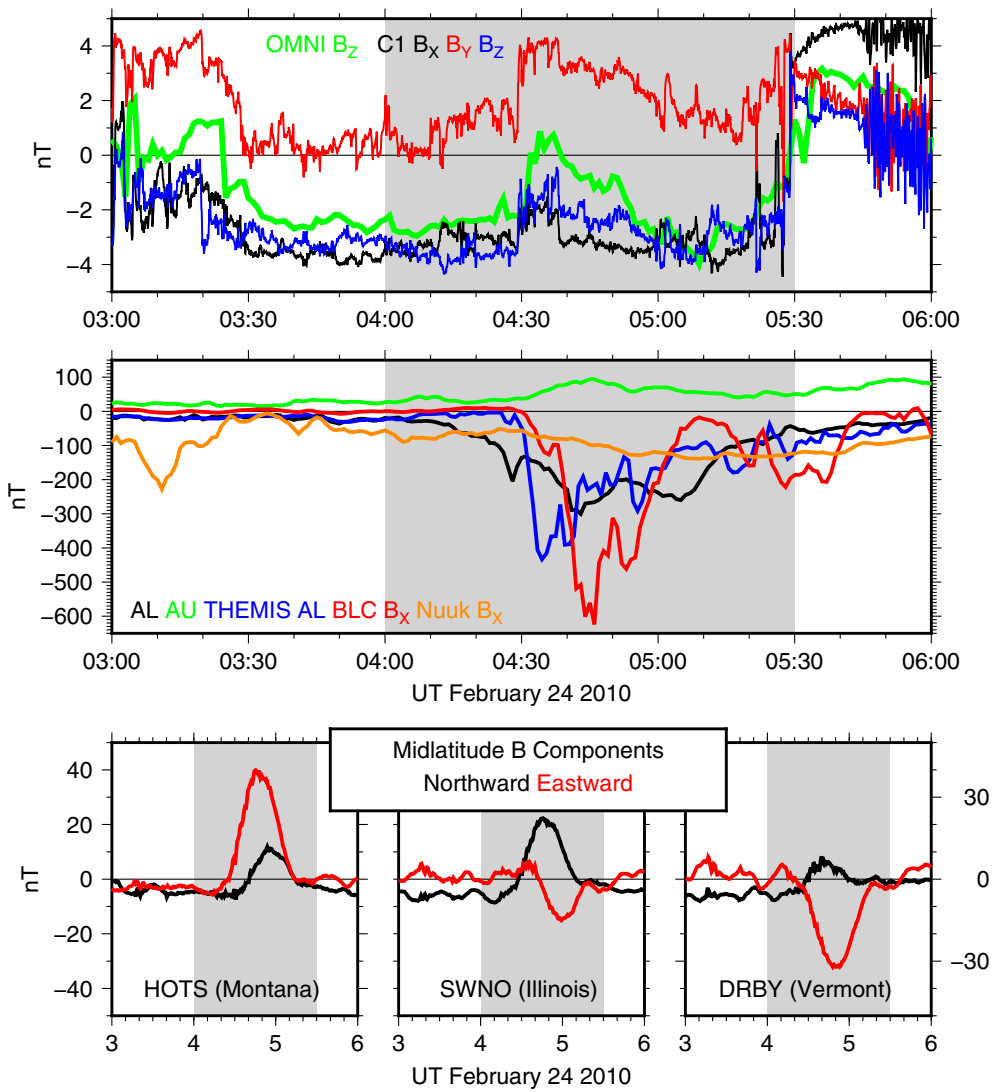

Fig. 1 Space and ground magnetic fields during the substorm event of February 24, 2010. The 4:00-5:30 UT period of interest is indicated with gray shading. The top panel shows OMNI propagated IMF northward component (green) and three components of the magnetic field measured by Cluster-1 just in front of the Earth's bow shock. At the end of the period shown, Cluster detected foreshock waves. The middle panel gives Standard AL (black), standard AU (green), THEMIS AL (blue), Baker Lake (BLC) magnetic north component, and Nuuk (Greenland) magnetic north component of ground magnetic field. The bottom panel shows midlatitude eastward (red) and northward (black) magnetic field components at midlatitude ground stations from west (left) to east (right) in North America 
data for IMF $B_{Z}$ is presented in green and found to generally agree with non-timeshifted Cluster $1 B_{Z}$ data shown in blue. Cluster 1 was at roughly $(15,0,-10) R_{E}$ in GSE coordinates, with a bow shock distance, measured along $\mathrm{X}$ at $Z=-15 R_{E}$, of about $3 R_{E}$ and magnetopause distance of about $7 R_{E}$, in the time period 4-5 UT relevant to onset timing, according to SSCweb (http://sscweb.gsfc. nasa.gov/) for the $1.3 \mathrm{nP}$ dynamic pressure typical of the period. Depending on the orientation of IMF structures, Cluster 1 may have been sampling essentially at the bow shock, whose GSE X nose position would have been about the same and about 3.5 $R_{E}$ from the magnetopause. OMNI data indicated a solar wind flow speed of about $360 \mathrm{~km} / \mathrm{s}$ and density of 5-6/cc during this period. In the case of radial flow, a time delay of as little as $1 \mathrm{~min}$ to the magnetopause could apply to the Cluster data. While OMNI $B_{Z}$ data could give the impression that the substorm was triggered by northward turning, the Cluster data shows a more complex behavior, with a large rotation from negative $B_{X}$ and $B_{Z}$ into $B_{Y}$, which changed from near-zero values to dominate the solar wind field in the period immediately after onset time. As indicated by the OMNI data, there was a definitive northward turning near 5:30 UT and, then, moving inward, Cluster detected what we interpret as foreshock waves toward the end of the period depicted.

The indices and data in the middle panel of Fig. 1 indicate fairly quiet conditions preceding onset, with the $\mathrm{AU}$ index slightly rising after southward turning (definitive by 3:25 UT at $-3 \mathrm{nT}$ according to both OMNI and Cluster). Standard AL was decreasing slowly before the nominal 4:30 onset time, and THEMIS AL, based on stations then available, dropped sharply at that time. It will be seen below that this envelope function was largely reflecting the behavior of station Rankin Inlet. Nearby station Baker Lake (not in THEMIS AL) dropped considerably more about $10 \mathrm{~min}$ after the nominal onset. Standard AL also did not reflect the activity well, which is often the case (Connors 2012). Northward component data from Greenland station Nuuk shows that no major substorm activity was seen there during the nominal substorm period, although some activity was detected immediately after southward turning. The bottom panel shows the subauroral perturbations used by Connors et al. (2014) to select the event due to their conformity to the SCW model.

Figure 2 shows the location of ground stations and satellite footprints. The THEMIS footprints were located east of Canadian ground stations, and as the Nuuk data of Fig. 1 shows, activity did not extend past them to Greenland. The station at Akulivik was part of the Polaris chain (Connors and Rostoker 2015), but data from other Polaris sites in the auroral zone was not available. The distribution of FAC measured by AMPERE nominally in the 4:38-4:40 UT time window is shown, transformed to geographic coordinates from the AAGCM coordinates of the data files using the routines of Shepherd (2014). The downward FAC not extending further east is consistent with the weakness of the substorm signals in Greenland, and THEMIS footprints were colocated with it. We show the footprint of GOES 12, which was GOES East at the time, for the time period 4-5 UT. As shown in Fig 3, GOES 12 detected a dipolarization during the event near the time of nominal onset. Figure 3 also shows the subauroral $B_{X}$ component perturbations at Shawano at larger scale, along with the filtered Pi 2 pulsations (40-150-s period) in that component. A vertical line at the time 04:26:21 UT shows what we later infer to be main substorm onset. Here, that is suggested by the rapid rise in inclination (i.e. dipolarization) at GOES synchronous orbit and less strongly by an inflection upwards in the $B_{X}$ component at Shawano. The Pi 2 pulsations, often used for substorm timing, do not give a very distinct onset signature in this case.

We now proceed to present optical data from the west coast of Hudson Bay and relate it to detailed images from nearby ground cameras. We then apply the automated meridian modeling (AMM) inversion technique (Connors and Rostoker 2015) to magnetic data from a "Churchill chain" made up of stations of several organizations and examine to what degree a simple uniform electrojet model represents this data. We explain individual magnetograms to insert some details that are missed by a uniform model, supplemented by a rough inversion of data from a single station in a critical location. We conclude that the event is best explained as a strong pseudobreakup or weak initial expansive phase, an expansive phase, and a poleward boundary intensification (PBI), using previous terminology. Finally, we connect the PBI to magnetic field changes detected by the THEMIS spacecraft near the midnight sector.

\section{Ground signatures Optical signatures}

The THEMIS mission (Angelopoulos 2008), whose five spacecraft were launched in 2007, has a ground segment made up largely of magnetometers and imagers, the latter housed in Ground Based Observatories (Harris et al. 2008), which image in white light at a cadence of 3 s. Relevant to the optical aspects of this study are three such imagers at Kuujuak, Gillam, and Rankin Inlet (see Fig. 2). Images were also available from Sanikiluaq but of limited utility due to cloud. The images overlap slightly, which allows creation of mosaics having a field of view larger than individual imagers, although below we have chosen to focus on time sequences of images from individual sites. It is also possible to make keograms, which in the case of east-west aligned auroral forms allow rapid interpretation of north-south motion. Keograms are generally 


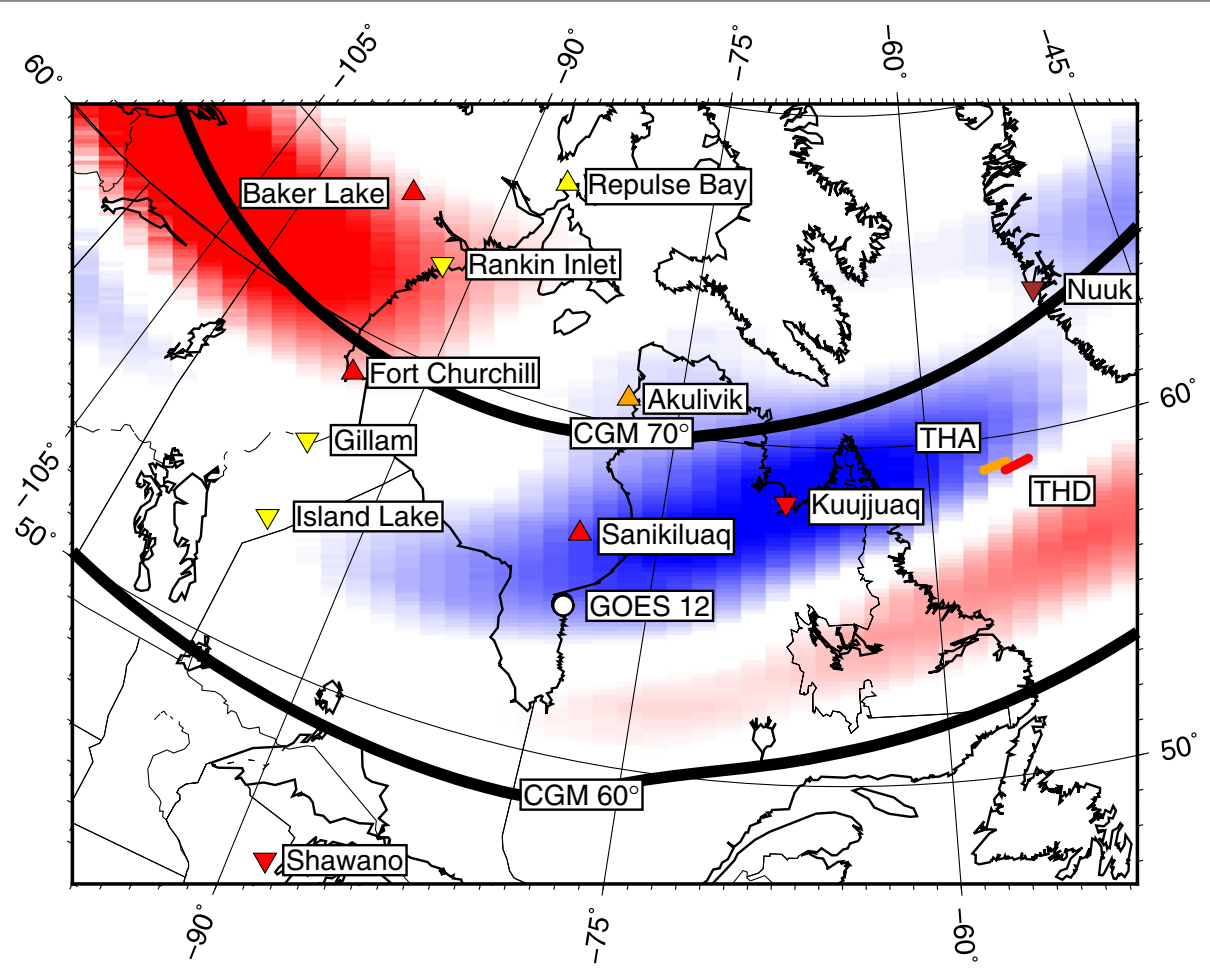

Fig. 2 Magnetometer stations and spacecraft footpoint locations $(K p=3)$ in the vicinity of AMPERE FAC (blue is downward, red upward, maximum density approximately $1 \mu \mathrm{A} / \mathrm{m}^{2}$ ) of the substorm current wedge at 4:39 UT February 24, 2010. THEMIS footpoints are for 4:27 to 4:39 UT, during which the footpoints move westward, and THEMIS A is in orange and THEMIS D in red. GOES 12 footpoint for the hour 4-5 UT is shown in as a white circle. Geomagnetic latitudes $60^{\circ}$ (bottom) and $70^{\circ}$ (top) are shown as heavy black lines labeled near $0^{\circ}$ geomagnetic longitude, which is near $-75^{\circ}$ geodetic longitude as labeled at the bottom and, in turn, is near magnetic midnight at this time. Locations of magnetometers of NRCan are shown by red triangles, CARISMA by inverted yellow triangles, MACCS by a yellow triangle, and Polaris by an orange triangle, THEMIS by a red inverted triangle, and DTU by a brown inverted triangle. Stations Rankin Inlet, Gillam, Sanikiluaq, and Kuujuaq have THEMIS all-sky imagers. The town of Fort Churchill hosts both the CARISMA magnetometer designated FCHU and the NRCan observatory FCC

made from the central strip in the north-south direction from each of a set of images, stacked beside each other to give a two-dimensional image in which the horizontal axis is time while the vertical axis is pixel row for a raw keogram but could be transformed to latitude. Figure 4 presents keograms from Gillam and Rankin Inlet to its north, stacked with slight overlap so as to give coverage over much of the auroral oval. As raw keograms, only the local zenith has a definitively known latitude, which is that of the station, and those zenithal locations are marked with station name in the figure. Approximate latitude scales are indicated based on image calibrations: these become nonlinear far from the zenith, and there is a gap in the scale in this region where an accurate calibration is not possible. The keograms are available in 1-h intervals from the THEMIS project; thus, a total of six keograms have been used to depict the results for two stations over $3 \mathrm{~h}$ shown in the figure. Cluster solar wind data identical to that of Fig. 1 has been placed above the keograms. Some growth phase auroral arcs (also visible in Fig. 5 near the southern border of the 04:12 images from
RANK and near the northern border of those from GILL) were clear in the interval 3:30 to 4:10 UT. We cannot exclude that these arcs are PBIs, and detailed examination of optical data shows temporary formation of streamers. The keogram shows some similarity to those shown by Nishimura et al. (2013) in which onset appears to be associated with equatorward motion of streamers. However, unlike in those cases, in this meridian, we see no more equatorward aurora at this early stage of the event: further, the equatorward motion is slower than in the Nishimura et al. (2013) study. Having been present through most of the growth phase to that point, these arcs dimmed shortly before 04:11 UT. Shortly after 04:11 UT (red vertical line), a faint feature moved southward and then brightened and moved northward. After 04:26:17 (orange vertical line), rapid northward motion of the auroras took place. This is a generally recognized characteristic of a substorm onset as observed near its central meridian. This motion persisted until approximately 4:40 UT, with a retreat of the poleward border, at first slowly, and then rapidly, near 5 UT. A very bright feature moved poleward again at about 

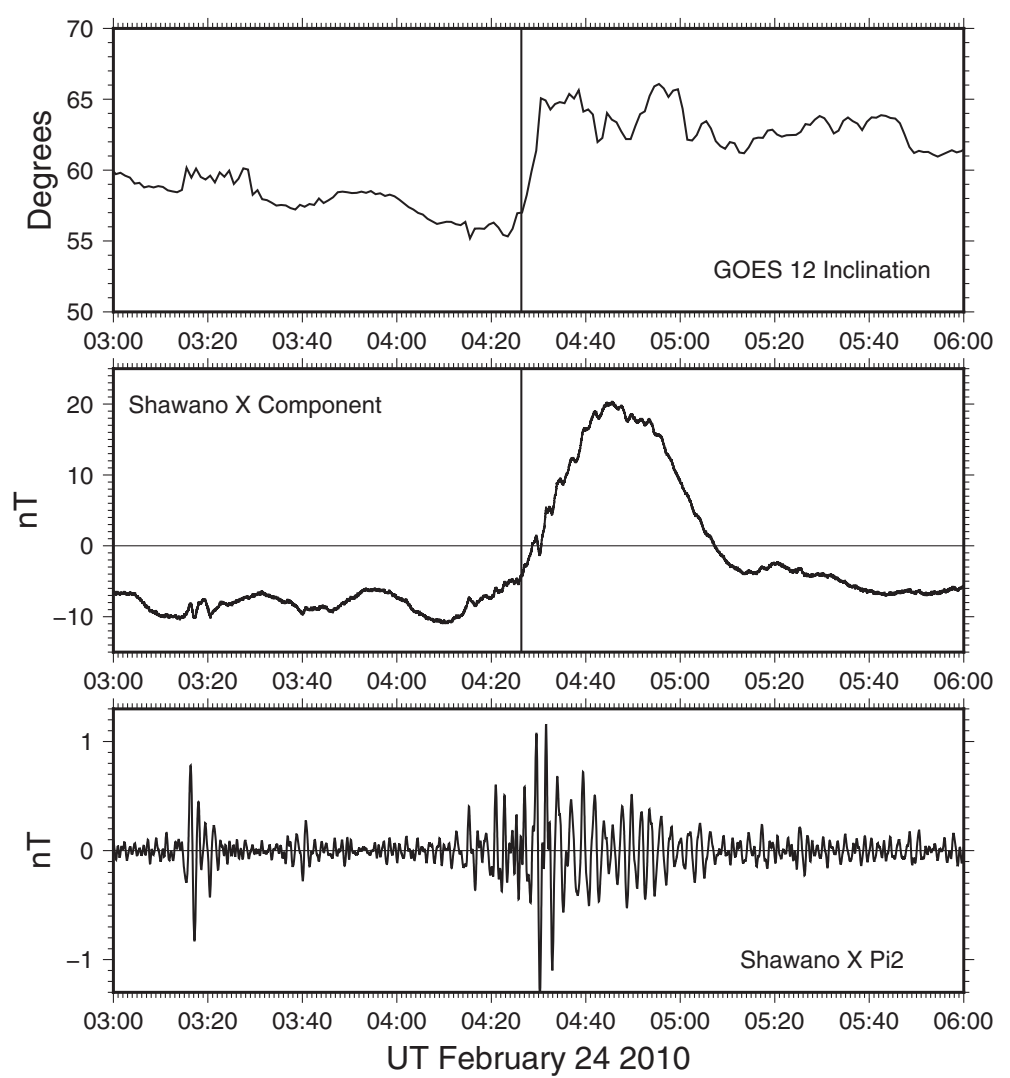

Fig. 3 Secondary onset indicators. The bottom panel shows the $B_{x}$ component Pi 2 waveform at Shawano. The middle panel shows the $B_{X}$ component perturbation magnetic field at Shawano, enlarging the trace in the middle of the bottom panel of Fig. 1. The top panel shows the inclination of the magnetic field at GOES 12. In the top two panels, the expansive phase onset time of 04:26:21 UT is indicated by a vertical line

5:15 UT, and after northward turning at 5:30 UT, bright aurora filled the sky at Rankin Inlet for a few minutes, followed by a signficant dimming of auroras. As noted above, we interpret the Cluster magnetic field to show foreshock waves after roughly 5:45 UT, which we interpret as due to spacecraft motion into a pre-existing wave structure, so there is no relation to an auroral brightening about that time. After the northward turning, there was a rapid dimming of auroras and we consider this to be recovery phase, which is not further discussed.

The optical picture of the substorm just presented conforms generally to the interpretation in Connors et al. (2014). However, there is clearly organized auroral activity prior to the nominal onset time, much as that study suggested there was magnetic activity. Starting about 4:16 UT (just left of, or before, the white bar which is missing data), a band of aurora brightened and moved poleward in a very systematic manner, remaining very narrow. It moved from one keogram to the other but appeared to stall in its motion as the nominal onset time approached. Since structuring of auroras can aid in establishing onset times (as for example in Liang et al. (2008)), and this structuring is not obvious in keograms, we now inspect all-sky image sequences near the potential times of interest. Figure 5 shows RANK and GILL for the minute 04:12 UT, and those stations and the more easterly one KUUJ in the several minutes following 04:26 UT (we return to the RANK 04:38 UT set below). The earlier pair shows an arc which had actually formed in the 04:11 UT minute near GILL but was not bright enough to present. This arc is seen in the top part of the GILL images, as it brightens and structures. The RANK images are essentially devoid of aurora although some remant of faded growth phase arcs is seen below the Moon (brightest spot in lower left). There is no indication that an auroral streamer from the north initiated the activity near GILL, as Nishimura et al. (2010) found to sometimes be the case. Although there are lunar reflections (in the optical system including the dome housing the camera) present in the images, the arc visible from GILL formed clearly in the 04:11 UT minute equatorward of the growth phase arcs, much in the fashion described by Akasofu (1964). As discussed, after a small amount of initial equatorward motion, it brightened and rapidly moved northward. However, the auroras did not become extremely active, nor did magnetic field perturbations as reflected by indices or any individual station 

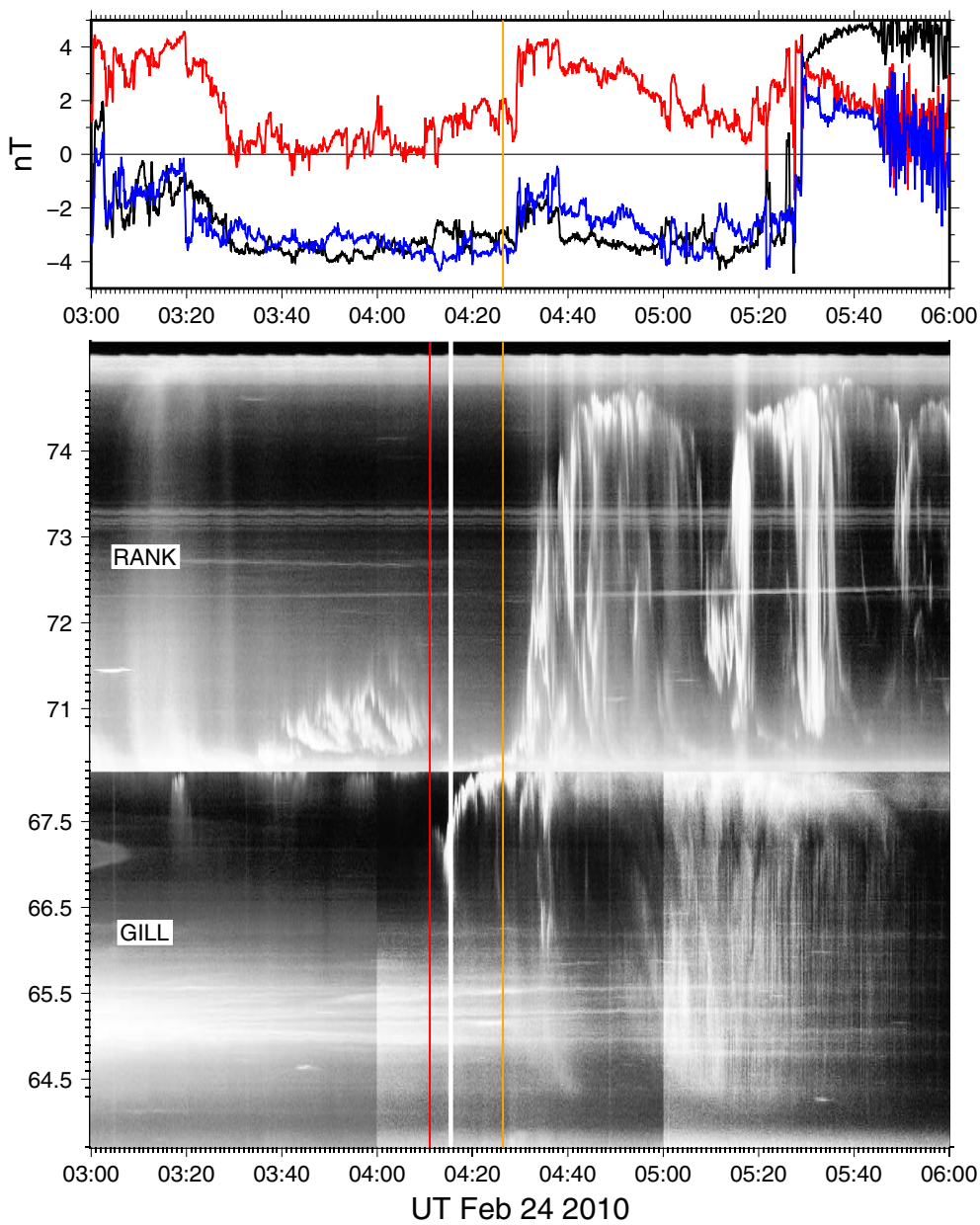

Fig. 4 THEMIS white light keograms from Gillam (bottom) and Rankin Inlet (top) overlain to show auroral motions in the station meridians, with Cluster IMF shown at top as in Fig. 1. Scales at the left indicate approximate geomagnetic latitude, and the labels GILL and RANK indicate the zenith at the respective stations. A vertical red bar marks 4:11 UT on the keogram for comparison to Fig. 6. A vertical orange line marks the expansive phase onset time of 04:26:21 UT in both panels. A vertical white line at ca. 4:17 UT is missing data in the keogram

records, until near the nominal onset time of Connors et al. (2014). As discussed in the "Introduction" section, there seems to be considerable overlap in the literature in the descriptions of pseudobreakups and full expansive phase onsets (especially in cases of "double onset"). We tend to regard this weak event as a pseudobreakup. The initiation of full onset seems to be indicated by the formation of a new arc between two pre-existing ones shown in the KUUJ 04:26 panel of Fig. 5. This arc structured and moved toward the east (right) rapidly within the 04:26 UT minute as seen from KUUJ. In the next minute, the arc which had developed out of the pseudobreakup brightened in the northern sky of GILL and also as seen on the southern horizon from RANK. The KUUJ and RANK/GILL images do not overlap, so we cannot determine the exact relation of the arc at KUUJ to the pre-existing one further west. As the keograms of Fig. 4 indicate, a very full expansion of aurora was observed after this time, and a strengthening of electric currents leading to perturbations large enough that (as also indicated by AMPERE current density integrations) Connors et al. (2014) identified 04:30 UT as the nominal onset time. We now proceed to examine ground magnetic fields for the event, both with a meridian inversion technique and as individual magnetograms.

\section{Magnetic inversion}

Much as it featured no bright aurora, the growth or pre-onset phase featured no consistently strong magnetic perturbations. In the hour 3-4 UT, the automated meridian modeling (AMM) inversion technique (Connors and Rostoker 2015) gave no meaningful results due to weak signal. Inversion results, which became meaningful after 4:20 UT with strengthening perturbations allowing solution, are shown for the period 4-6 UT in Fig. 6. The bottom panel shows in black the cross-meridian current 


\section{RANK/GILL 04:12}
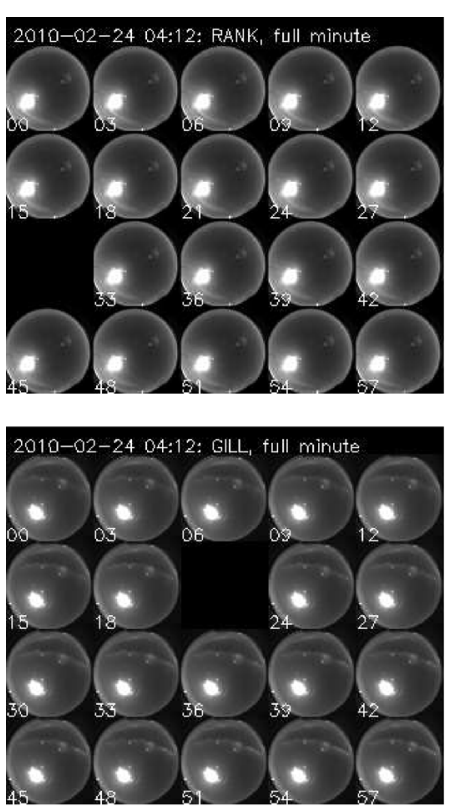

RANK 04:38

\section{RANK/GILL/KUUJ}
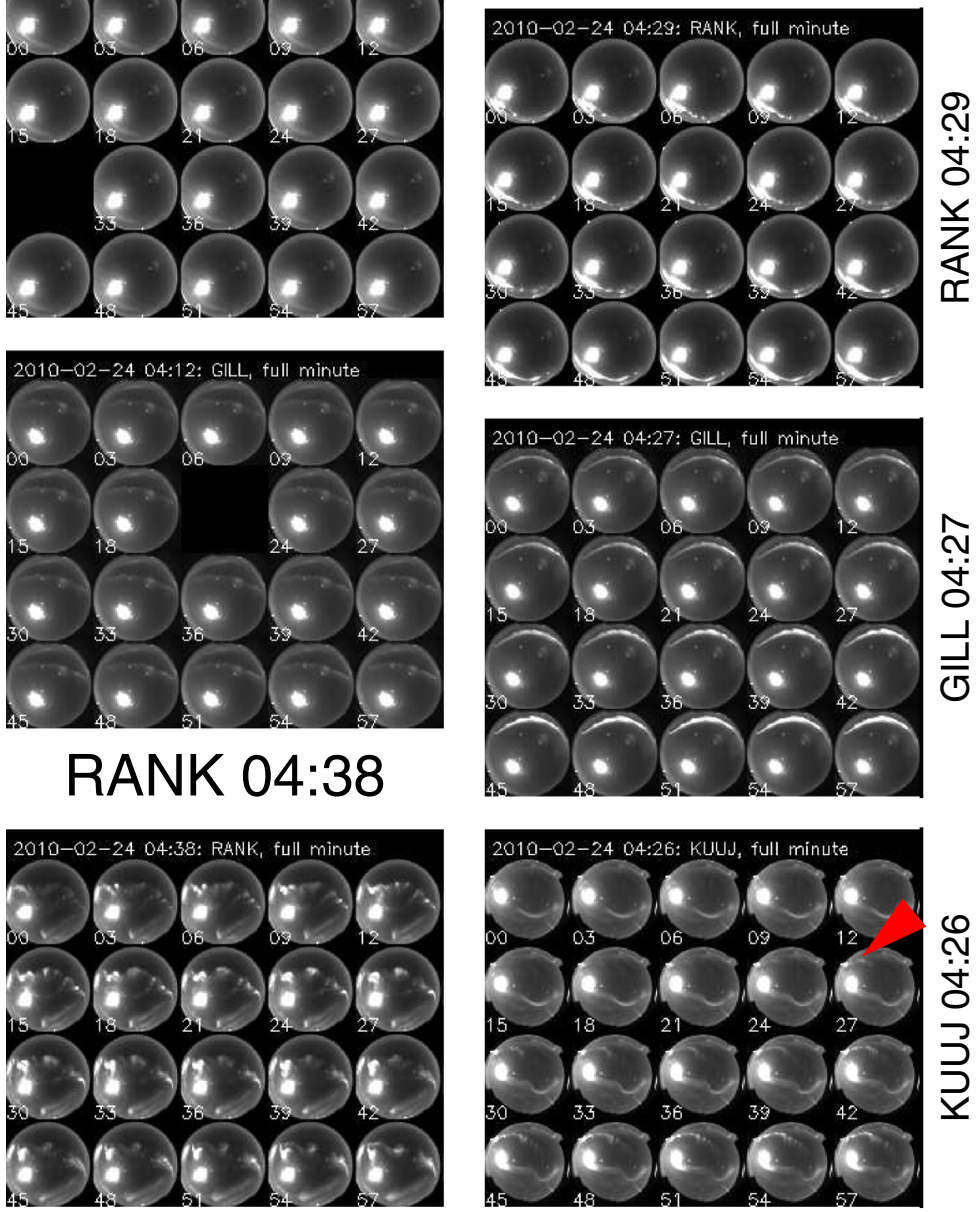

Fig. 5 One-minute ASI sequences of 3-s cadence all-sky images at ground stations, highlighting auroral structuring and intensifications. Within each panel, the time sequence is to the right and down (like reading text). Within each image, north is at the top and east to the right. In all images, a bright spot to the left or lower left is the Moon. The top left panels show RANK/GILL images whose central pixels form part of the keogram of Fig. 4. A growth phase arc is visible below the Moon in the RANK images, while the upper part of the GILL images is traversed by a brightening arc which first became visible in the previous minute. The right column shows RANK/GILL and KUUJ at the times indicated at the right of each image. A new arc which became visible at 04:26:21 at KUUJ is highlighted at 04:26:27 by a red arrow. This new arc formed structure and moved toward the east in the field of view. At the lower left, a single panel shows brightening and structuring of the polemost arc at RANK in the minute of 04:38 UT

in the Churchill line, whose amplitude AMM suggested maximized at nearly $0.7 \mathrm{MA}$. We show in red the results of the more general inversion technique automated forward modeling (AFM) in its regional variant, as applied to a set of North American stations by Connors et al. (2014), which do not exceed 0.5 MA westward. Connors and Rostoker (2015) discuss that AFM applied on a meridian with field-aligned currents in the model constrained to be very distant is similar to finding equivalent currents. On the other hand it is inferred in (Connors et al. 2014), as supported by AMPERE data, that application to a set of distributed stations gives physical parameters, i.e., the real current. We do not examine this point further here but return to the fact that the regional inversion gave a smaller current than the meridian approach. AMPERE current density data as integrated by (Connors et al. 2014) gave a value of about $0.6 \mathrm{MA}$ in the SCW system, not decisively favoring either modeling result. Nevertheless, for the reasons discussed below, we feel that AMM has overestimated the current.

The electrojet borders shown in the middle panel of Fig. 6 exhibit extremely similar behavior to that of auroral luminosity in the keograms of Fig. 4. After pseudobreakup (red line in both figures), there was a rapid rise of the 

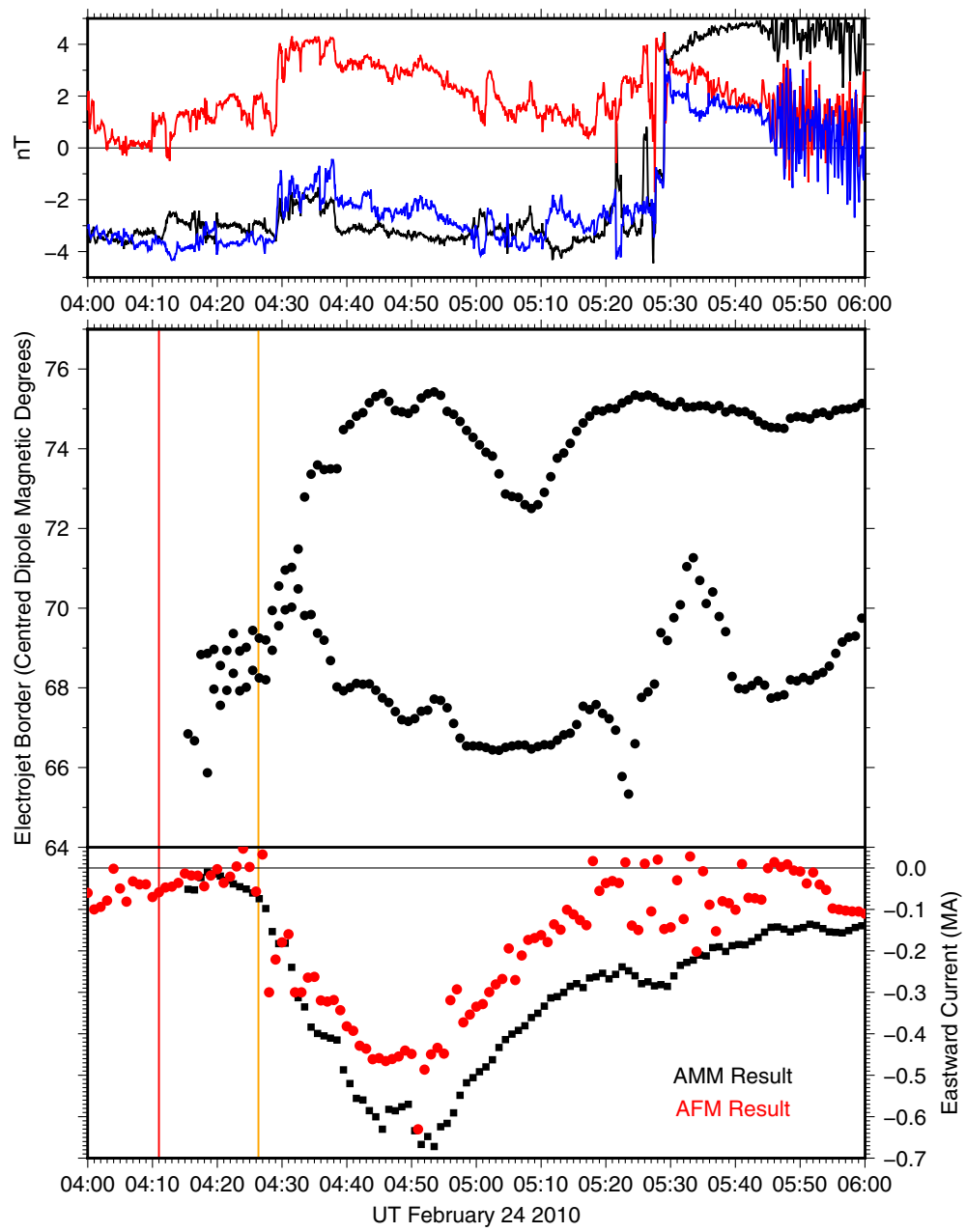

Fig. 6 Automated forward modeling results in the Churchill meridian for 4:00 to 6:00 UT on February 24 2010. Red (left border) and yellow vertical lines are as in Fig. 4. The bottom panel shows eastward cross-meridian current, a negative value since the current was westward, as black dots from meridian modeling and as red dots from a three-dimensional model based on a sparse continent-wide dataset. The middle panel shows electrojet borders from meridian modeling. The top panel shows the Cluster IMF as in previous plots. Timing bars in the inversion results are as in Fig. 4

poleward border, which then stalled until expansive phase onset (orange line in both figures). Within a few minutes of this, the current had dramatically strengthened and the electrojet borders widened, much as in the keogram the aurora brightened and expanded to fill the nearly the entire meridian at RANK. Auroras and electrojet diminished in intensity and returned to lower latitudes by 5:10 UT, a timescale of about one half hour. The equatorward border is somewhat ill-defined in the keogram (due to being near the horizon for both stations) but does not show extreme motion for an hour after nominal onset and neither does that from the inversion. They both move northward about 5:30 UT but not in good synchrony. In the period before 4:30 UT, the small (less than 0.1 MA magnitude) current was confined to a narrow latitudinal width and moved northward, much as a distinct auroral band also was seen to do in the keogram. Some of this period was not well-defined in AMPERE integration (Connors et al. 2014), due to overly small (i.e., below noise threshold) current densities.

Inversion, consistent with auroral keograms, suggests a behavior reminiscent of expansive phase onset but with weak currents, prior to what we have clearly identified to be full expansive phase onset at 04:26:17 UT. Again, we feel it is most suitable to consider this earlier period to be a pseudobreakup. We now examine the fit of the magnetograms to determine how significant the above results are and to resolve the discrepency about overall magnitude of current.

\section{Ground magnetic fields}

Figure 7 shows the observed (solid lines) and modeled (dots) magnetic perturbations for the northward $B_{X}$ (black) and downward $B_{Z}$ (blue) components used in 


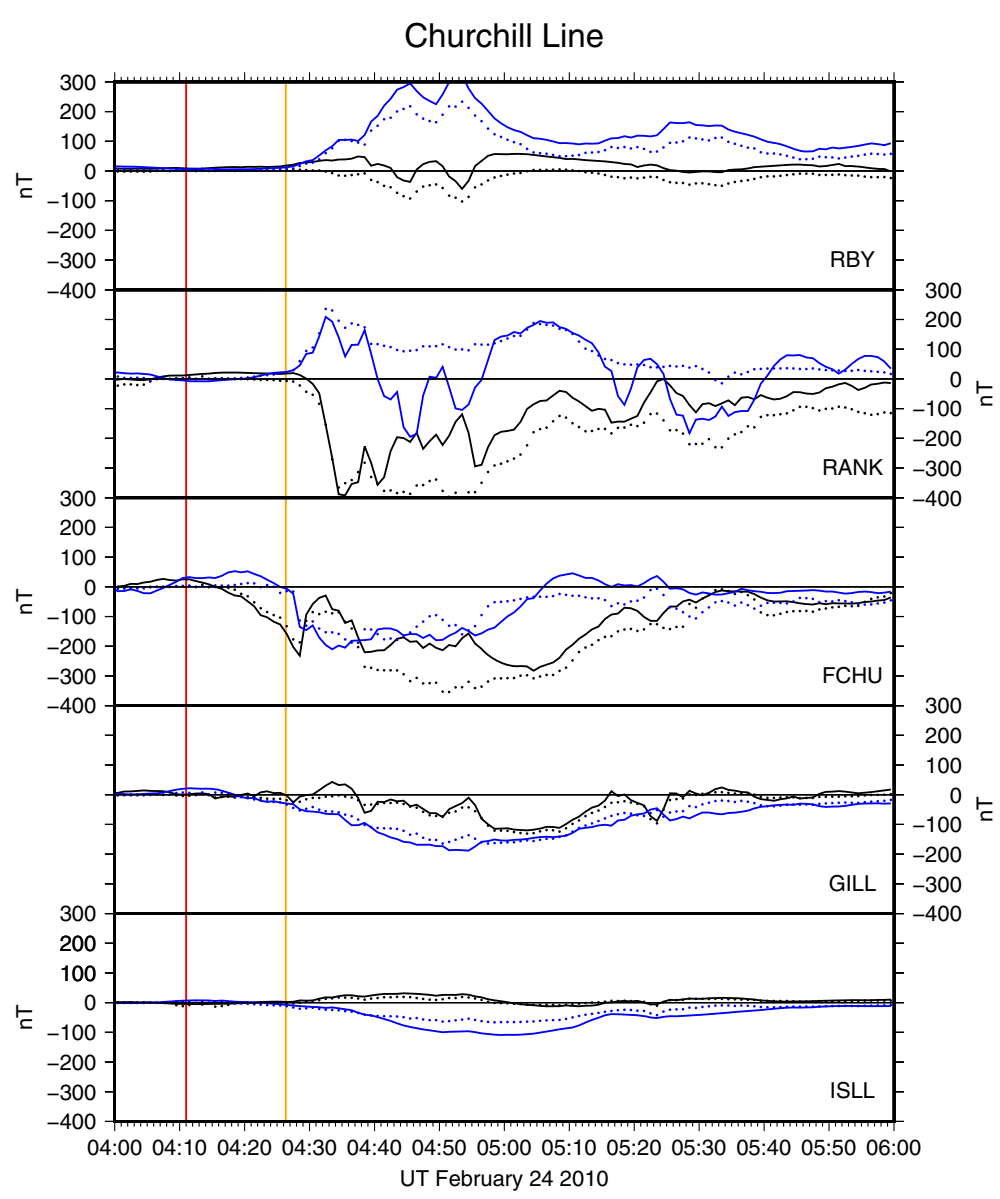

Fig. 7 Comparison of observed (solid lines) and modeled (dots) magnetic field perturbations in the Churchill meridian from 4:00 to 6:00 UT on February 24, 2010. The $B_{X}$ component is plotted in black and the $B_{Z}$ component in blue. See text for discussion. Timing bars as in Fig. 4

inversion for the five auroral zone stations in the Churchill meridian whose details are given in Table 1 . The largest perturbations were at Fort Churchill and Rankin Inlet, and data from these stations entered the optimization calculation with one third the weight of that from the other stations. In tests, if equal weighting was applied, a poor agreement was found at the outlying stations, with those dominant stations extremely well-matched. A

Table 1 Stations used in inversion. Map names used in Fig. 2 are in the left column, codes used in plots of results in second column

\begin{tabular}{llllll}
\hline Station & Code & $\begin{array}{l}\text { Geodetic } \\
\text { latitude }\end{array}$ & $\begin{array}{l}\text { Geodetic } \\
\text { longitude }\end{array}$ & $\begin{array}{l}\text { Magnetic } \\
\text { latitude }\end{array}$ & $\begin{array}{l}\text { Magnetic } \\
\text { longitude }\end{array}$ \\
\hline Resolute Bay & RBY & 66.52 & 273.77 & 76.0 & 345.0 \\
Rankin Inlet & RANK & 62.82 & 267.89 & 72.77 & 326.12 \\
Fort Churchill & FCHU & 58.80 & 265.9 & 68.64 & 325.96 \\
Gillam & GILL & 56.38 & 265.36 & 66.21 & 326.49 \\
Island Lake & ISLL & 53.86 & 265.34 & 63.73 & 327.56 \\
\hline
\end{tabular}

more detailed discussion of station weighting is given by Connors and Rostoker (2015), but here, we note that a good overall match to the observations was given by a simple electrojet model with only the three parameters, north and south electrojet borders and cross-meridian current, shown in Fig. 6. To the north, station RBY detected little $B_{X}$ perturbation and positive $\mathrm{Z}$, well-matched by the model. To the south, the negative $B_{Z}$ perturbations indicating a westward electrojet to the north were wellmatched at GILL and ISLL. The near-zero $B_{X}$ at ISLL and negative $B_{X}$ at GILL are consistent with their locations relative to the electrojet also. During much of the event, the match at FCHU and RANK was also good. However, the match was poor at those two main auroral oval stations between 4:36 and 5:00 UT.

The nature of the discrepancy is that FCHU has too much negative $B_{X}$ in the model, as does RANK. In addition, RANK in the model has a slightly positive $B_{Z}$, while in reality $B_{Z}$ was slightly negative there. Both of these indicate that there is too much current near the stations: $B_{X}$ 
arises basically from overhead current, and the uniform electrojet model places too much over each station in the middle of the auroral oval. In addition, the net current location is south of RANK in the model to give it a $+B_{Z}$ perturbation, whereas in reality the current spent most of the interval on average north of RANK to give it a $-B_{Z}$ perturbation. It is clear that the electrojet had a more complex structure than the simple uniform model gave. That stucture is likely a splitting of the electrojet into a double auroral oval. If the gap was over RANK and FCHU, then $B_{X}$ would decrease in magnitude (i.e., have a less negative value), and if the missing current was north of RANK, it would show a $-B_{Z}$ perturbation. The missing current could conceivably decrease the overall magnitude of the electrojet for better agreement with the AMPERE values. We will proceed to run a rather extreme form of AFM model which is illustrative of the concept of a bifurcated electrojet and then return to a more general discussion of what magnetic signatures tell us about the time sequence of the substorm.

The most intense magnetic perturbations detected in the event were at station Baker Lake, centrally located in northern Canada (see Fig. 2), and exceeded 600 nT in the $B_{X}$ component, exceeding the magnitude of the AL index by a factor of approximately 2 , and the real-time THEMIS AL (which was calculated from an arbitrary number of stations as an envelope, but did not include BLC) by a similar factor at times. Since there are no other stations to make a chain with BLC, we attempted single-station inversion on its $B_{X}$ and $B_{Z}$ component data. Here, we obtain three output parameters for two input data points, so the results are only indicative. They are comparable to making arguments based on application of Ampere's Law as a simple right hand rule and our discussion is in that vein. Figure 8 shows the single-station inversion results for BLC for 4:30 to 5:10 UT (a slightly longer time axis is used to allow clear labeling). At 4:30, the current was already strong enough that it had an effect at BLC as the decreasing $B_{X}$ and rising $B_{Z}$ component (bottom panel) indicate. The poleward border rises and descends much as in Fig. 6 and as seen in the keogram of Fig. 4. This fact inspires some confidence in the reality of this model. Where it differs is that rather than a wide electrojet, it finds a narrow one, about $1^{\circ}$ wide as it rises and about $2^{\circ}$ wide when at maximum latitude. The current needed to reproduce the data varies between about 0.2 and $0.4 \mathrm{MA}$ westward but averages about 0.3 MA. The parameters in the top panel allow a remarkable degree of reproduction of the input data, as seem in the bottom panel. This aspect is not surprising as there is an "extra" parameter available to allow a good fit to only two input values at each timestep. The implications of this small numerical experiment are that there likely was an enhanced poleward border of the poleward expanding substorm westward electrojet. At 0.3 MA, it had about half the current of the overall SCW electrojet, confined in a $1^{\circ}-2^{\circ}$ latitudinal extent. In Fig. 4 , it may be seen that this corresponds to the width of the brightness at the poleward border, that is to say, this current may be associated with a single auroral arc. In principle, we could put such a second current set into our model and have a nonuniform electrojet. In practice, the wide station spacing available on this chain does not support adding extra parameters, as they would be poorly constrained.

\section{Substorm timing}

The preceding signatures allow a more detailed examination of the sequence of activity, which we will organize through selected magnetograms (see Fig. 9). In addition to Baker Lake, whose $B_{X}$ component was shown in Fig. 1, the nearby station Rankin Inlet (RANK) and observatory Churchill (FCC) roughly $5^{\circ}$ southward in the same meridian are shown (see Fig. 2). Yet further south, and roughly $1 \mathrm{~h}$ of magnetic local time further east is Sanikiluaq (SNK). Both FCC and SNK (since roughly 2005, replacing Poste de la Baleine) are standard AE stations. Since AL is a lower envelope, and this substorm was localized in North America, FCC and SNK determined AL after approximately 4:15 UT, the green line indicating AL following the $B_{X}$ trace either for FCC or for SNK. For this event, the $\mathrm{AE}$ was nonlocal in that it jumped between stations. It also missed the amplitude of activity by a large margin and never showed the large steep drops often taken as characterizing substorms in AL. More using individual magnetograms than indices, we now try to put together the events of the early part of this substorm. We also use the keogram and timing from the images.

Southward turning having taken place about 3:20 UT and with a relatively steady IMF $B_{Z}$ value near $-3 \mathrm{nT}$, a growth phase took place. The AU index increased and the $B_{X}$ component at Nuuk decreased (Fig. 1), indicating current flowing in the evening and morning sectors, respectively. Growth phase equatorward moving arcs were detected at RANK. After their dimming, a new arc formed in the minute of 04:11 UT. This time is marked by a vertical red line in Fig. 9, and at this time, the $B_{X}$ component at both FCC and SNK began decreasing: by 4:15 UT, these had become negative and were decreasing, to the point that AL was dominated by one or the other through the remainder of the event. It is primarily $B_{X}$ and $B_{Z}$ perturbations at FCC/FCHU (Fig. 9) that allow magnetic modeling of the initial arc that moved poleward during the pseudobreakup. We placed expansive phase onset at 04:26:21 UT, shown by an orange line in Fig. 9. At approximately this time, the $B_{X}$ component at FCC became more negative by about $100 \mathrm{nT}$, while that at SNK became less negative by a similar amount. The $B_{Z}$ component at FCC soon became negative by $200 \mathrm{nT}$ and that at SNK slightly so. At FCC, this corresponds to an electrojet (westward 


\section{Current Parameters for Single Station Electrojet Model}

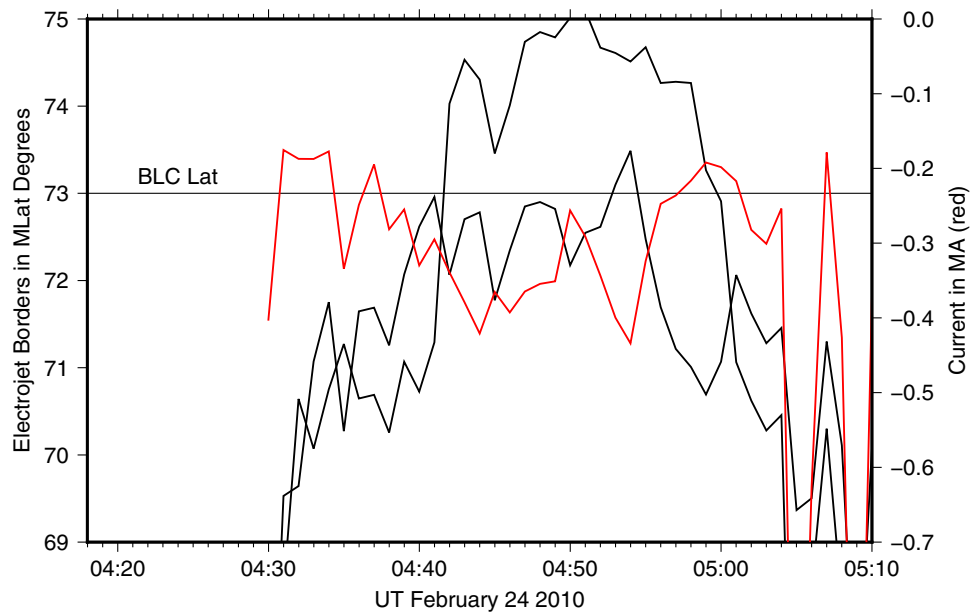

Baker Lake Observation and Model

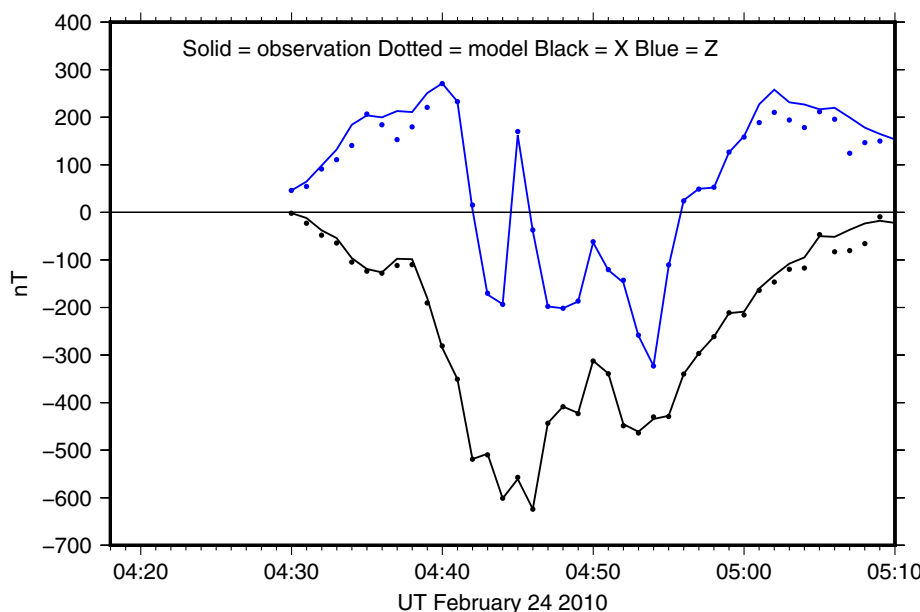

Fig. 8 Local inversion results from the single-station Baker Lake (BLC) for 4:30 to 5:10 UT on February 24, 2010. The bottom panel shows observations and model results as in Fig. 7. The top panel shows inversion results as in Fig. 6 but plotted on the same panel with latitude key to the left and current key to the right. The latitudinal borders are plotted in black and the cross-meridian current in red

ionospheric current) north of the station. Prior to 4:26 UT, the $B_{X}$ component at FCC had been negative and the $B_{Z}$ positive, indicating an electrojet south of the station. During this period, the $B_{X}$ was negative at SNK and $B_{Z}$ close to zero, the signal of a near-overhead current. The $B_{Z}$ component at RANK and to a lesser extent, that at BLC, started to increase at 4:26 UT and the $B_{X}$ to decrease. These are signals of an electrojet south of the stations, moving northward. This northward motion continued for several minutes, but about 04:33 UT, the electrojet greatly widened and the keogram indicates aurora no longer confined to a single arc but filling nearly the entire sky at RANK. In Fig. 9, this time corresponds to the maximal negative $B_{X}$ component perturbation at RANK and large positive $B_{Z}$ (electrojet south of station) at BLC. With these stronger magnetic signals and full auroral expansion, we are justified in considering this to be an expansive phase, as opposed to the weaker earlier intensification which we class as a pseudobreakup.

The final phase of intensification of the event began at approximately 4:38 UT. At this time, structured aurora north of the expansive phase arc brightened once more and definitively. The initiation of structuring and brightening is shown in the RANK field of view in the bottom left panel of Fig. 5. In the keogram of Fig. 4, this brightening is visible over a large latitude range (although no time bar is shown). Referring to the magnetograms, a large decrease in the $B_{X}$ component at BLC started at 4:38 UT and led to the largest perturbations, over $600 \mathrm{nT}$, observed in the event. Initially, $B_{Z}$ became more positive, indicating further poleward movement of the nearby electrojet, but at 4:40 UT, this had ceased. We can thus 


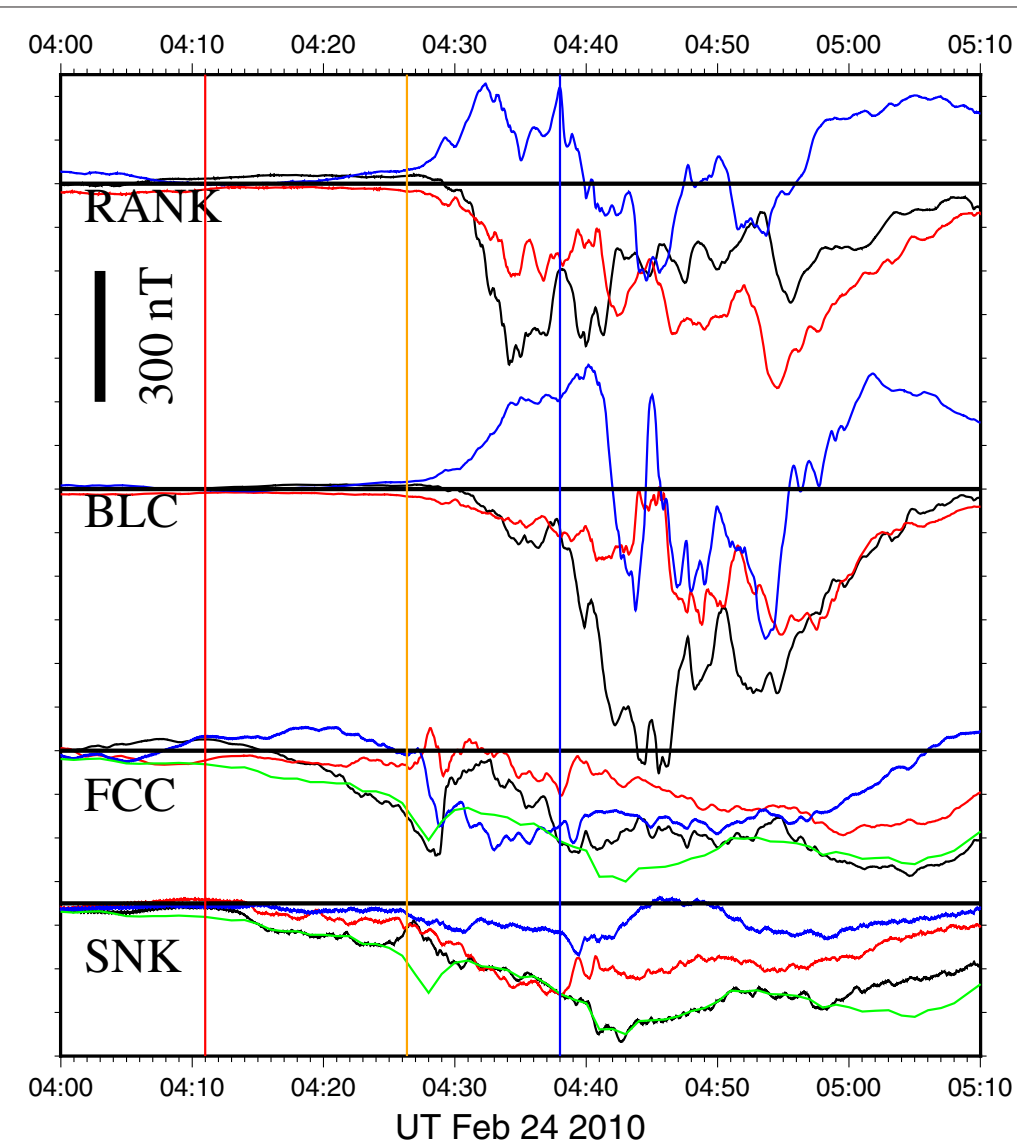

Fig. 9 Individual magnetograms from stations on or near the Churchill meridian from 4:00 to 5:10 UT on February 24, 2010. BX, $B_{Y}$, and $B_{Z}$ component perturbations are indicated in black, red, and blue, respectively. The standard AL index is marked in orange on the bottom two panels for comparison to AE stations SNK and FCC (which is the NRCan observatory at Fort Churchill). Timing bars as in Fig. 4, with addition of a blue bar indicating 04:38 UT

infer that further decrease in the $B_{X}$ component after that time reflected an actual increase in current rather than motion of the electrojet, which is consistent with the AFM inversion (including the single-station version). At RANK, slightly south and to the east of BLC, decrease in both $B_{X}$ and $B_{Z}$ is consistent with poleward motion of a strengthening electrojet already north of the station. After 4:40, decreases in both $B_{X}$ and $B_{Z}$ components indicate a strengthening electrojet north of BLC. Finally, a relatively stable period with the arc stalled at the poleward border of the auroral oval (no aurora further poleward is seen) ensued. We refer to this final phase of expansion as the poleward boundary intensification (PBI).

To summarize, we find that a growth phase that initiated with southward turning ended with a fading of auroras and formation of a new arc at approximately 04:11 UT in the late evening sector near GILL (Gillam). This arc moved poleward but bright auroras remained restricted to its vicinity, and magnetic fields did not intensify greatly. Inversion results show a maximal current during this phase of about 0.08 MA (Fig. 6). Initial poleward motion of auroras and currents that started at 4:11 stalled out. This we regard as a pseudobreakup phase. There ensued what we regard as the true expansive phase, whose onset we identify rather precisely as being at 04:26:17 UT, with the formation of an arc at KUUJ between two pre-existing ones. This activity in turn appeared to reach a maximal extent by 4:38 UT but with bright all-sky auroras, magnetic perturbations of over $500 \mathrm{nT}$, and current of order 0.5 MA. We regard this as full expansive phase. After that point, renewed activity appeared to be a PBI, which in fact featured the largest currents of the whole substorm, greater than 0.5 MA and peaking about 04:50 UT. We do not consider here the activity that took place later in the substorm, whose declining activity began about 4:54 with current decrease and poleward border retreat, except to note that after the strong northward turning at 5:30 UT, auroras faded rapidly and currents less so. Rather, we proceed to associate the PBI at 4:38 UT with changes at the THEMIS spacecraft, with emphasis here on magnetic fields. 


\section{Spacecraft observations in morning sector}

During the period of interest, three THEMIS spacecraft were in the early morning sector, and magnetic field data is shown in Fig. 10 along with the ground magnetic field from Akulivik, a station in the then-extant Polaris network (Connors and Rostoker 2015) whose position is shown in Fig. 2. Mappings for THEMIS A and D along field lines for $\mathrm{Kp}=3$ were shown in Fig. 2, and comparison to AMPERE (Fig. 2) and inversion results of Connors et al. (2014) shows them to be near the location of downward FAC of the substorm current wedge near the time of the PBI. THEMIS A was at GSM $(-8.77,-3.64,-2.72)$ at $4: 30 \mathrm{UT}$ and was near the southern plasma sheet boundary layer (PSBL), as the $-B_{X}$ field during the event shows. THEMIS $\mathrm{D}(-8.83,-3.77,-2.05)$ and $\mathrm{E}(-8.81,-3.57,-2.08)$ were close to each other, about $0.65 R_{E}$ above THEMIS A, and very close to the neutral sheet, with near-zero field components along X. Their magnetic field signatures were similar, and only those from THEMIS D are shown in Fig. 10. After the IMF southward turning at 3:25 UT, the $B_{Z}$ component at all three spacecraft decreased starting at about 3:40, and about the same time, the $B_{X}$ field at A decreased irregularly (not shown). These are well-known growth phase signatures in the respective regions of the near-Earth magnetotail. There were no notable changes at the time of the 04:11 UT pseudobreakup, likely confirming its localized nature. About 4:26 UT, the time inferred for the start of the expansive phase, all components of the field at all three spacecraft started to show irregular variations, of amplitude about $5 \mathrm{nT}$ in the plasma sheet and $2 \mathrm{nT}$ in the PSBL. This time also marked the start of dipolarization in the neutral sheet, a return to $B_{X}$ and $B_{Z}$ values before the growth phase changes. At THEMIS D, a rapid decrease in the $B_{X}$ component took place about $2 \mathrm{~min}$ after onset, possibly indicating a travel time delay from the midnight sector. At Akulivik, a short duration negative $B_{X}$ excursion of about $-200 \mathrm{nT}$ took place. Had this location been available for inclusion in the THEMIS AL index, 4:26 UT would likely have appeared to have been the beginning of the substorm expansive phase. The $-B_{X}$ signature there decreased at 4:30 UT but strengthened again to $-200 \mathrm{nT}$, with $+B_{Z}$ of a similar size indicating current to the south of the station.

All three spacecraft showed abrupt but short duration field changes at 4:38 UT, the time of PBI onset. These included most notably decreases in all field components

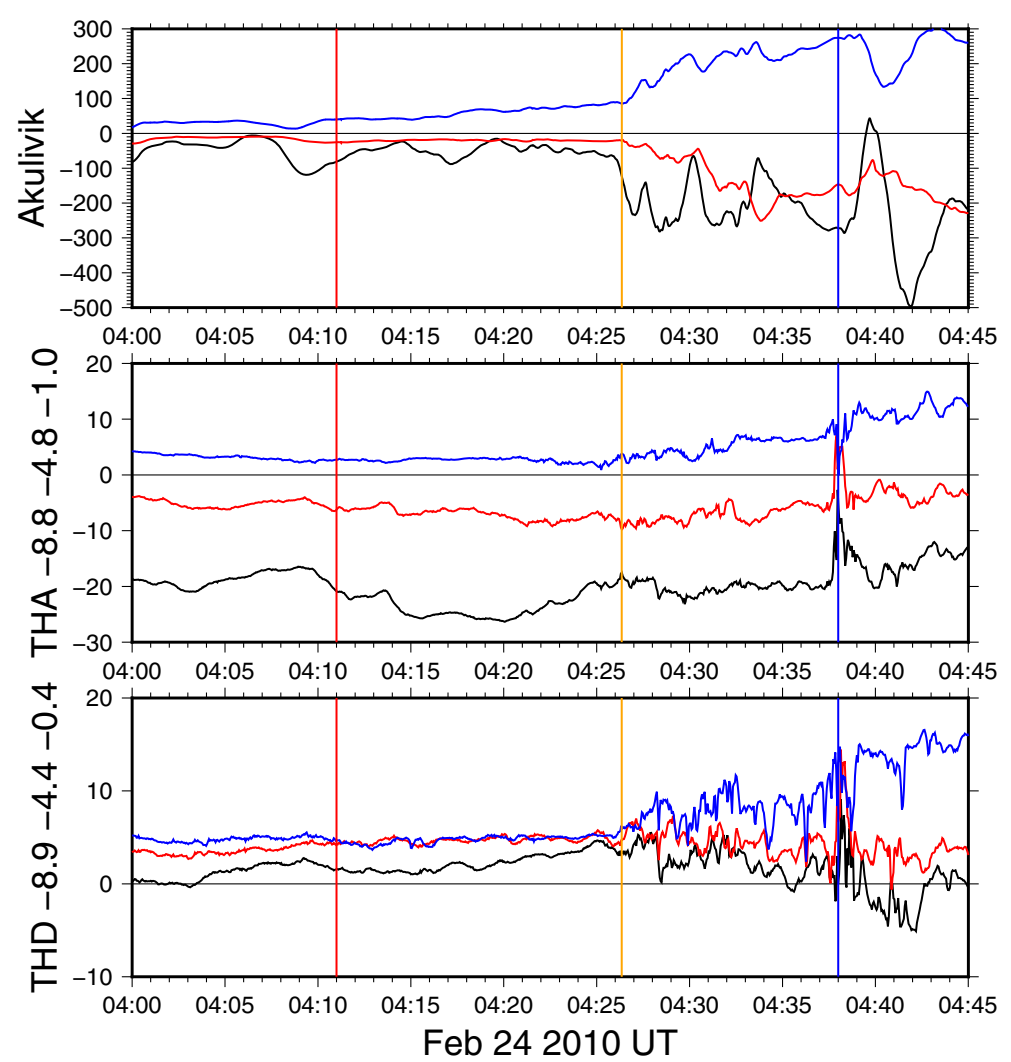

Fig. 10 Comparison of THEMIS D (bottom), THEMIS A (middle), and Akulivik magnetic fields from 4:20 to 4:45 UT on February 24, 2010. The spacecraft data are in GSE coordinates, with spacecraft positions at 4:30 UT shown in the caption. The ground magnetic fields are in local magnetic coordinates. Color coding for components with the same designation in both systems are $B_{X}$ (black), $B_{Y}$ (red), and $B_{Z}$ (blue). Timing bars as in Fig. 9 
at THEMIS A. After a dropout to near-zero $B_{X}$ component value, Akulivik showed an enhanced electrojet signal of $-500 \mathrm{nT}$ briefly, associated probably with the PBI, and approaching the value observed at Baker Lake. After the PBI signal in space, the THEMIS D (and E, not shown) spacecraft had dipolarized mainly through increase in the $B_{Z}$ component. THEMIS A showed a lesser degree of dipolarization. Large amplitude flows were seen at these spacecraft near this time. We also note that THEMIS C, in the magnetotail's morning sector and near $X=-40$ $R e$, showed Earthard flows of up to $400 \mathrm{~km} / \mathrm{s}$ through much of the active period. Space does not permit detailed discussion of flow signals here, but the three inner magnetosphere THEMIS spacecraft showed large flows only at the time of the PBI. Since they were on the edge of the SCW as indicated by its detected downward current, they provide little information on possible more central flows.

\section{Discussion}

The present detailed analysis gives a picture of the February 24, 2010 substorm which reflects many of the characteristics deduced over the years by studies mentioned in the "Introduction" section. To the overall description of the expansive phase given by Connors et al. (2014), we add a pseudobreakup having taken place about 15 min before the onset time, which is in itself advanced by about $4 \mathrm{~min}$ from their nominal time of 4:30 UT. We also found that a PBI, about $12 \mathrm{~min}$ after the revised onset time, led to the strongest magnetic field perturbations of the event, mainly clear from the ground through analysis of individual high-latitude night-time sector magnetograms, but with a close association to early morning sector magnetic field changes about $9 R_{E}$ downtail but not in the central plasma sheet.

Russell (2000) proposed a model in which substorms in two steps could reflect the action of the near-Earth neutral line (NENL), while a more distant neutral line injected plasma into the inner magnetosphere. The present observations do not have adequate spacecraft coverage near the EP onset region to determine if NENL flow activity was involved, as was inferred by Angelopoulos et al. (2010) for a different event. The PSBL activity associated with the final PBI, along with the inward flow from the region of THEMIS C, likely speaks to the action of a more distant reconnection site at that later time. Mishin et al. (2001) found for several substorms that a pattern in which an "initial onset" (which they identified with pseudobreakups or trigger bays) took place at low latitude, followed by a "second onset" at higher latitude. After the first onset, flux continued to accumulate in the magnetotail, while the second onset, which they associated with northward turning of the IMF, released it. Our interpretation is broadly in agreement with such two-step models of substorms, possibly adding PBI phenomenology to the second step. We note that while propagated solar wind data (OMNI in Fig. 1) could have suggested an association with northward turning for the original nominal onset time of Connors et al. (2014), in fact, the EP onset was earlier, and the solar wind change featured more of a rotation than a simple northward turning.

\section{Conclusion}

We have made a detailed examination of a substorm chosen as prototypical and ostensibly simple, found by Connors et al. (2014) to have an onset time of 4:30 UT. We found that the active substorm sequence started earlier, consisting of an initial pseudobreakup at 4:11 UT, a substorm expansive phase onset whose breakup arc we identified at 04:26:17 UT, and a poleward boundary intensification at 4:38 UT, covering a period of about $40 \mathrm{~min}$. In the local time sector with clear images, we saw no evidence of triggering by inbound auroral streamers, but instead, that auroral activity moved poleward with the development of the substorm sequence. We could relate activity in space (GOES and THEMIS) to the sequential activations observed in magnetic fields and optical observations on the ground in a one-by-one manner for the expansive phase and the PBI but could not detect the pseudobreakup. This is consistent with its limited current and extent of longitudinal growth. We could quantitatively model the magnetic fields associated with the poleward motion of an arc and electrojet associated with the pseudobreakup and the expansive phase in general, using optical and magnetic data from the Churchill meridian. There ensued a PBI, whose ground magnetic fields dominated the entire event but whose distinct nature was not clear using data only from that meridian. THEMIS spacecraft in the early morning sector showed an increase in variability in magnetic field, and in the plasma sheet a dipolarization, associated with EP onset. GOES 12, closer to the activity, showed a strong dipolarization signal then. Later, coincident with the PBI, all three THEMIS spacecraft, in the early morning sector and near the SCW downward current at the time, registered large B field changes.

We have explained the nature of magnetic fluctuations early in the substorm which Connors et al. (2014) did not account for. We found that the substorm sequence was built from the previously familiar elements of pseudobreakup, expansive phase, and PBI. Some remaining aspects of this event that appeared puzzling have not been addressed (duration of upward FAC in evening sector, conjugacy). However, we have revealed another aspect deserving further study, which is the relation of a large solar wind field rotation to substorm onset. For a single event, the fact that onset happened out of a pseudobreakup when a large rotation took place may merely be a coincidence. However, this event likely does have 
adequate data from the four Cluster spacecraft to enable a very accurate study of solar wind timing, comparable to what we have established using ground data, to explore this possible link.

Classifying the parts of a substorm does not in itself lead to understanding of the nature of those parts for one event. However, the methods illustrated here may be more widely applied and may lead to analysis in the sense of breaking substorms into parts that can be understood. In this particular event, the path to physical understanding may be easiest for the PBI late in the event, for which both ground and satellite data are available.

\section{Abbreviations}

AFM: automated forward modeling; AMM: automated meridian modeling; AMPERE: active magnetosphere and planetary electrodynamics response experiment; $B_{X}, B_{Y}, B_{Z}$ (ground): northward, eastward, and downward magnetic field perturbations, in local magnetic coordinates; $B_{X}, B_{Y}, B_{Z}$ (space): sunward, prograde, and toward north ecliptic pole magnetic field components, in GSE coordinates; EP: expansive (expansion) phase; FAC: field-aligned current; GOES: geostationary operational environmental satellite (geosynchronous); IMF: interplanetary magnetic field; NENL: near-Earth neutral line; PBI: poleward boundary intensification; PBU: pseudobreakup; PSBL: plasma sheet boundary layer; $R_{E}$ : Earth radius; $S C W$ : substorm current wedge; XYZ (on ground): northward, eastward, and downward directions, here in local magnetic coordinates; XYZ (in space: here GSE or GSM as specified) sunward, prograde, and north directions

\section{Competing interests}

The authors declare that they have no competing interests.

\section{Authors' contributions}

MC carried forward a previous study in collaboration and discussion with the other authors. All authors read and approved the final manuscript

\section{Acknowledgements}

The authors thank U. Auster, K.H. Glassmeier, W. Baumjohann, and A. Balogh and E. Lucek, for, respectively, THEMIS and Cluster magnetic data, obtained from CDAWeb. For ground magnetometer data, the authors acknowledge $\mathrm{E}$. Steinmetz and M. Engebretson of Augsburg College; I. Mann of the University of Alberta, and the Canadian Space Agency; the THEMIS project; C. Stolle and J. Matzka of DTU Space, Denmark; and NRCan for CANMOS and Polaris data. The authors thank E. Donovan of the University of Calgary and the Canadian Space Agency for ground optical data. We acknowledge NASA contract NAS5-02099 and V. Angelopoulos for use of data from the THEMIS Mission. We thank J.H. King and N. Papatashvilli for OMNI data, downloaded from CDAWeb. We thank the AMPERE project for Iridium-derived data products and $\mathrm{H}$. Korth for the assistance in their interpretation.

\section{Author details}

'Athabasca University Observatories, 1 University Drive, Athabasca AB T9S 3A3, Canada. ${ }^{2}$ IGPP, UCLA, Los Angeles, CA, USA.

Received: 1 May 2015 Accepted: 9 November 2015

Published online: 03 December 2015

\section{References}

Akasofu S-I (1964) The development of the auroral substorm. Planet Space Sci $12: 273-282$

Akasofu S-I (2004) Several controversial issues on substorms. Sp Sci Rev 113:1-40

Anderson BJ, Korth H, Waters CL, Green DL, Merkin VG, Barnes RJ, Dyrud LP (2014) Development of large-scale Birkeland currents determined from the active magnetosphere and planetary electrodynamics response Experiment. Geophys Res Lett 41:3017-3025

Angelopoulos V (2008) The THEMIS mission. Space Sci Rev 141:5-34 doi:10.1007/s11214-008-9336-1
Angelopoulos V, McFadden JP, Larson D, Carlson CW, Mende SB, Frey H, Phan T, Sibeck DG, Glassmeier K-H, Auster U, Donovan E, Mann IR, Rae IJ, Russell CT, Runov A, Zhou X-Z, Kepko L (2010) Tail reconnection triggering substorm onset. Science 321:931-335

Angelopoulos V, Runov A, Zhou X-Z, Turner DL, Kiehas SA, Li S-S, Shinohara I (2013) Electromagnetic energy conversion at reconnection fronts. Science 341:1478-1482

Birkeland K (1908) The Norwegian Aurora polaris expedition 1902-3, Part 1. A Aschehoug, Christiania, Norway

Connors M (2012) Comment on "Substorm growth and expansion onset as observed with ideal ground spacecraft THEMIS coverage" by V. Sergeev et al. J Geophys Res 117. doi:10.1029/2011JA017254

Connors M, McPherron RL, Anderson B, Korth H, Russell CT, Chu X (2014) Electric currents of a substorm current wedge on 24 February 2010. Geophys Res Lett 41:4449-4455. doi:10.1002/2014GL060604

Connors M, Rostoker G (2015) Inverting magnetic meridian data using nonlinear optimization. Earth Planets Space 67:155. doi:10.1186/s40623-015-0315-y

Elvey CT (1957) Problems of auroral morphology. Proc Nat Acad Sci 43:63-75

Harris SE, Mende SB, Angelopoulos V, Rachelson W, Donovan E, Jackel B, Greffen M, Russell CT, Pierce DR, Dearborn DJ, Rowe K, Connors M (2008) THEMIS ground based observatory system design. Space Sci Rev 141:213-233. doi:10.1007/s11214-007-9294-z

Heppner JP (1954) Time sequences and spatial relations in auroral activity during magnetic Bays at College, Alaska. J Geophys Res 59:329-338

Liang J, Donovan EF, Liu WW, Jackel B, Syrjäsuo M, Mende SB, Frey HU, Angelopoulos V, Connors M (2008) Intensification of preexisting auroral arc at substorm expansion phase onset: Wave-like disruption during the first tens of seconds. Geophys Res Lett 35:L17S19. doi:10.1029/2008GL033666

Lyons LR, Nagai T, Blanchard GT, Samson JC, Yamamoto T, Mukai T, Nishida A, Kokubun S (1999) Association between Geotail plasma flows and auroral poleward boundary ntensifications observed by CANOPUS photometers. J Geophys Res 104:4485-4500

Lyons LR, Voronkov IO, Donovan EF, Zesta E (2002) Relation of substorm breakup arc to other growth-phase auroral arcs. J Geophys Res 107. doi:10.1029/2002JA009317

Lyons LR, Nishimura Y, Xing X, Runov A, Angelopoulos V, Donovan E, Kikuchi T (2012) Coupling of dipolarization front flow bursts to substorm expansion phase phenomena within the magnetosphere and ionosphere. J Geophys Res 117:A02212. doi:10.1029/2011JA017265

McPherron RL (1970) Growth phase of magnetospheric substorms. J Geophys Res 75:5592-5599

McPherron RL, Russell CT, Aubry MP (1973) Satellite studies of magnetospheric substorms on August 15, 1968, 9. Phenomenological model for substorms. J Geophys Res 78:3131-3149

Mishin VM, Saifudinova T, Bazarzhapov A, Russell CT, Baumjohann W, Nakamura R, Kubyshkina M (2001) Two distinct substorm onsets. J Geophys Res 106:13105-13118

Murphy KR, Mann IR, Rae IJ, Waters CL, Frey HU, Kale A, Singer HJ, Anderson BJ, Korth H (2013) The detailed spatial structure of field-aligned currents comprising the substorm current wedge. J Geophys Res 118:7714-7727. doi:10.1002/2013JA018979

Murphy KR, Mann IR, Rae IJ, Walsh AP, Frey HU (2014) Inner magnetospheric onset preceding reconnection and tail dynamics during substorms: can substorms initiate in two different regions? J Geophys Res 119:9684-9701. doi:10.1002/2014JA019795

Nishimura Y, Lyons L, Zou S, Angelopoulos V, Mende S (2010) Substorm triggering by new plasma intrusion: THEMIS allsky imager observations. $J$ Geophys Res 115:A07222. doi:10.1029/2009JA015166

Nishimura Y, Lyons LR, Shiokawa K, Angelopoulos V, Donovan EF, Mende SB (2013) Substorm onset and expansion phase intensification precursors seen in polar cap patches and arcs. J Geophys Res 118:2034-2042. doi:10.1002/jgra.50279

Potemra T (1985) Field-Aligned (Birkeland) Currents. Sp Sci Rev 42:295-311

Pu ZY, Chu XN, Cao X, Mishin V, Angelopoulos V, Wang J, Wei Y, Zong QG, Fu SY, Xie L, Glassmeier K-H, Frey H, Russell CT, Liu J, McFadden J, Larson D, Mende S, Mann I, Sibeck D, Sapronova LA, Tolochko MV, Saifudinova TI, Yao ZH, Wang XG, Xiao CJ, Zhou XZ, Reme H, Lucek E (2010) THEMIS observations of substorms on 26 February 2008 initiated by magnetotail reconnection. J Geophys Res 115:A02212. doi:10.1029/2009JA014217 
Rae IJ, Mann IR, Angelopoulos V, Murphy KR, Milling DK, Kale A, Frey HU, Rostoker G, Russell CT, Watt CEJ, Engebretson MJ, Moldwin MB, Mende SB, Singer HJ, Donovan EF (2009) Near-Earth initiation of a terrestrial substorm. J Geophys Res 114:A07220. doi:10.1029/2008JA013771

Rae IJ, Watt CEJ, Mann IR, Murphy KR, Samson JC, Kabin K, Angelopoulos V (2010) Optical characterization of the growth and spatial structure of a substorm onset arc. J Geophys Res 115:A10222. doi:10.1029/2010JA015376

Rostoker G (1968) Macrostructure of geomagnetic Bays. J Geophys Res 73:4217-4229

Rostoker G (2002) Identification of substorm expansive phase onsets. J Geophys Res 107:SMP 26-1-SMP 26-9. doi:10.1029/2001JA003504

Rostoker G, Akasofu S-I, Foster J, Greenwald RA, Kamide Y, Kawasaki K, Lui ATY, McPherron RL, Russell CT (1980) Magnetospheric substorms-definition and signatures. J Geophys Res 85:1663-1668

Russell CT (2000) How northward turnings of the IMF can lead to substorm expansion onsets. Geophys Res Lett 27:3257-3259

Sergeev VA, Kubyshkina MV, Baumjohann W, Nakamura R, Amm O, Pulkkinen T, Angelopoulos V, Mende SB, Klecker B, Nagai T, Sauvaud J-A, Slavin JA, Thomsen MF (2005) Transition from substorm growth to substorm expansion phase as observed with a radial configuration of ISTP and Cluster spacecraft. Ann Geophys 23:2183-2198

Shepherd SG (2014) Altitude-adjusted corrected geomagnetic coordinates: definition and functional approximations. J Geophys Res 119. doi:10.1002/2014JA020264

Yao ZH, Pu ZY, Owen CJ, Fu SY, Chu XN, Liu J, Angelopoulos V, Rae IJ, Yue C, Zhou X-Z, Zong Q-G, Cao X, Shi QQ, Forsyth C, Du AM (2014) Current reduction in a pseudo-breakup event: THEMIS observations. J Geophys Res 119:8178-8187. doi:10.1002/2014JA020186

\section{Submit your manuscript to a SpringerOpen ${ }^{\circ}$ journal and benefit from:}

- Convenient online submission

- Rigorous peer review

- Immediate publication on acceptance

- Open access: articles freely available online

- High visibility within the field

- Retaining the copyright to your article

Submit your next manuscript at $\gg$ springeropen.com 